\title{
Más que flores. Novedades sobre la trayectoria y producción artística del pintor José Romá (Valencia, 1784-1852)
}

\author{
María José López Terrada \\ Universitat de València \\ M.Jose.Lopez@uv.es
}

RESUMEN: El objetivo del presente artículo es contribuir al conocimiento de la trayectoria académica y de la producción artística de José Romá (Valencia, 1784-1852). Se trata de un importante artista de la primera mitad del siglo XIX, poco conocido en la actualidad, principalmente por sus lienzos de flores. Este estudio da a conocer nuevas pruebas documentales que demuestran sus aspiraciones a convertirse en «pintor de Historia», aporta información sobre su formación y su variada actividad pictórica e incluye un análisis de una composición de flores hasta ahora desconocida.

PALABRAS CLAVE: José Romá; Academia de Bellas Artes de Valencia; Pintura española del siglo XIX; Coleccionismo privado; Bodegón.

\section{More than Flowers. New Data about the Career and Artistic Production of the Painter José Romá (Valencia, 1784-1852)}

ABSTRACT: Our aim in this article is to expand our understanding of José Romá's academic training and artistic production. Romá, although barely remembered today, was a prominent artist during the first half of the nineteenth century, known mainly for his flower canvases. To this end, the study brings to light new documentary evidence that demonstrates his desire to become a «painter of historical scenes», adduces information concerning his training and varied pictorial activity, and includes an analysis of a heretofore unknown floral composition by Romá.

KEYWORDS: José Romá; Fine Arts Academy of Valencia; $19^{\text {th }}$ Century Spanish Painting; Private Collecting; Stillife.

Recibido: 10 de enero de 2018 / Aceptado: 4 de mayo de 2018.

En el año 2006, el Museo del Prado adquirió, junto a otras obras, una composición de flores de José Romá [1]. Con este motivo se realizó una exposición en cuyo texto se hacía referencia a este pintor como discípulo de la Academia de Bellas Artes de San Carlos y de Benito Espinós, así como a su cargo de director de la Sala de Flores de esta institución (Portús, 2007: 21, 95). El cuadro, una Guirnalda de flores con motivo escultórico realizado al óleo sobre lienzo de 46 × $56 \mathrm{~cm}$ fue detalladamente descrito dos años más tarde por J. J. Luna, que destacó su rica variedad floral e identificó como Hebe a la figura femenina que aparece en la moldura central. Su análisis concluía nuevamente con una alusión a este puesto (2008: 53-54). No obstante, este artista fue mucho más que un excelente pintor de flores, tanto por su labor docente como por su diversa actividad pictórica1.

Comencemos ofreciendo una visión de la trayectoria del artista donde se integran nuevos datos documentales de su paso por la Academia de San Carlos que demuestran sus innegables aspiraciones a convertirse en "pintor de Historia". La primera noticia relevante de este discípulo de Vicente López corresponde al año 1801, cuando opositó al premio de 3. ${ }^{a}$ Clase de Pintura en el Concurso General. Gracias a la consulta de las actas de este evento (Continuación: 1802) es posi-

Cómo citar este artículo: LÓPEZ TERRADA, María José, «Más que flores. Novedades sobre la trayectoria y producción artística del pintor José Romá (Valencia, 17841852)", Boletín de Arte-UMA, n. ${ }^{\circ}$ 39, Departamento de Historia del Arte, Universidad de Málaga, 2018, pp. 155-168, ISSN: 0211-8483, DOI: http://dx.doi.org/10.24310/ BoLArte.2018.v0i39.3986 


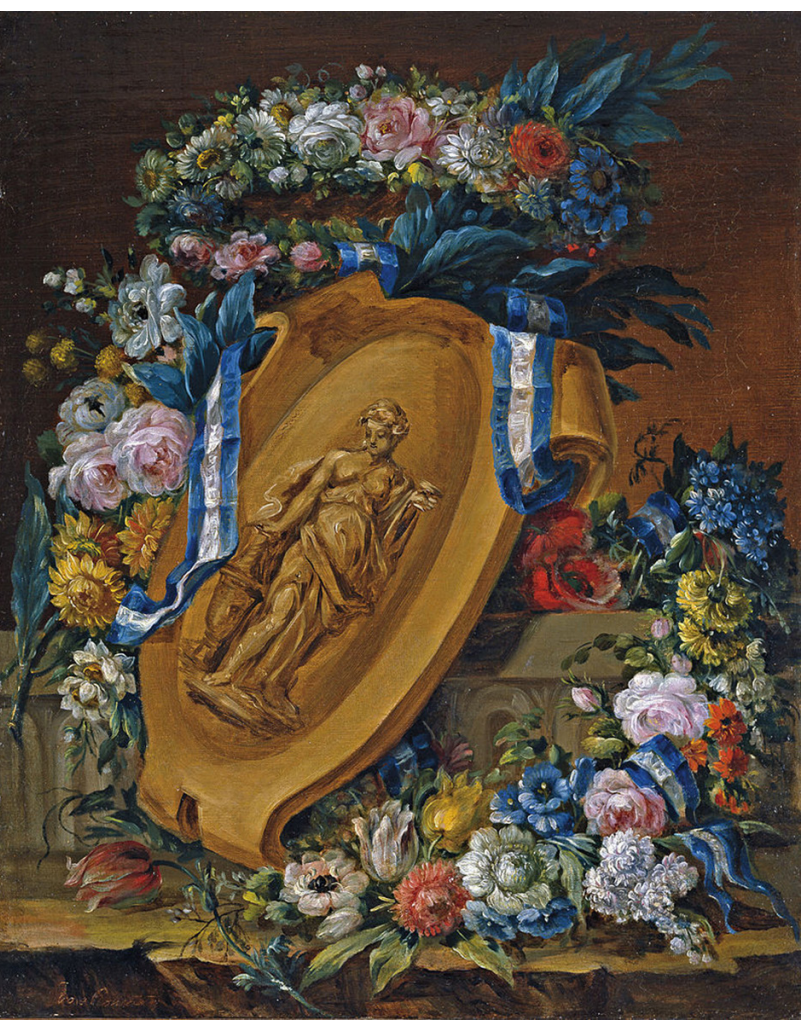

1. José Romá, Guirnalda de flores con motivo escultórico. (C) Museo Nacional del Prado

ble dar a conocer los temas propuestos para la obtención del premio, pues las obras de Romá no se han conservado. Como ejercicio «de pensado», debían dibujar «la estatua del Ídolo Egipcio» y como «repente», «la estatua del Mercurio de la bolsa». Optaron a este premio Francisco Llácer, que consiguió el galardón y que también opositó a la $3 .^{a}$ clase de Flores, como Vicente Martín; Luis Calvo, José Lloria, Salvador Gafiero y Jerónimo Navases.

Las siguientes noticias que ofreció Aldana sobre este pintor corresponden al año 1805 (1970: 197-198). Sin embargo, existe una huella anterior, no mencionada hasta el momento, que lo sitúa como opositor a la 2. ${ }^{a}$ Clase de Pintura en el Concurso General de 1804. Como se recoge en las actas (Continuación: 1805), el asunto del ejercicio «de pensado» fue: «Llegan las Marías al Sepulcro de Jesu Christo (sic) y advierten que este Señor había ya resucitado». El tema del ejercicio «de repente» consistió en: «Nerón hace morir en su presencia a Séneca». En este caso, los dos únicos oposito- res al premio fueron Romá y Francisco Llácer, que volvió a ganar. Sin embargo, no todo fueron derrotas, pues el 27 de abril de 1805 se le adjudicó, por unanimidad, el primer premio mensual en la Clase del Natural ${ }^{2}$. Afortunadamente, la obra premiada, una Academia, se conserva en el Museo de Bellas Artes de Valencia [2]. Es un dibujo realizado con lápiz negro y tiza sobre papel verjurado de 412 x 590 mm, con dos desnudos masculinos sentados. En el mismo Museo existen otras seis Academias de Romá difíciles de datar, pues unas fueron realizadas durante su etapa como discípulo y otras corresponden a su época como docente en la institución ${ }^{3}$.

Pero volvamos a 1805, año en el que Romá también accedió a la Sala de Flores. Las posibles causas de este ingreso fueron señaladas por Pérez Sánchez (1997: 35):

En Valencia, la demanda de la burguesía fue, sin duda, amplia, pues en los últimos años del siglo XVIII se multiplicaron los pintores de flores, y el éxito de algunos de ellos, con un prestigio que rebasa incluso lo local, debió mover a muchos aspirantes a emprender el camino de la pintura floral. La Sala de Flores y Ornatos les facilitaba el acceso, aunque sus propósitos fuesen otros.

La Sala de «Flores, Ornatos y otros diseños adecuados para los Tejidos» comenzó a funcionar en la Academia de San Carlos en 1778. Su creación estuvo determinada por la necesidad de formar pintores especializados en el diseño textil capaces de crear modelos originales que asegurasen la independencia de las sederías valencianas. Esta Sala se convirtió en la Escuela de Flores y Ornatos seis años más tarde, a partir de la Real Orden de 1784. En ella, Carlos III equiparó oficialmente estos estudios con las restantes enseñanzas académicas y nombró como director al «Maestro de Flores» Benito Espinós (1748-1818), que ocupó su puesto hasta el año 1815 y con el que se formó Romá. A partir de esta fecha, el responsable de la dirección de estos estudios fue José Antonio Zapata (1763-1837)

Como discípulo de la Sala de Flores, Romá obtuvo el segundo premio de la especialidad en el Concurso General de 1807. Hasta el momento, este era el único dato que se conocía al respecto, puesto que las actas con los premios de 1807 y 1810 no fueron impresas por las «circunstancias del estado de guerra» (Garín, 1945: 99). Gracias a la consulta de los manuscritos del archivo de la Academia, hemos 


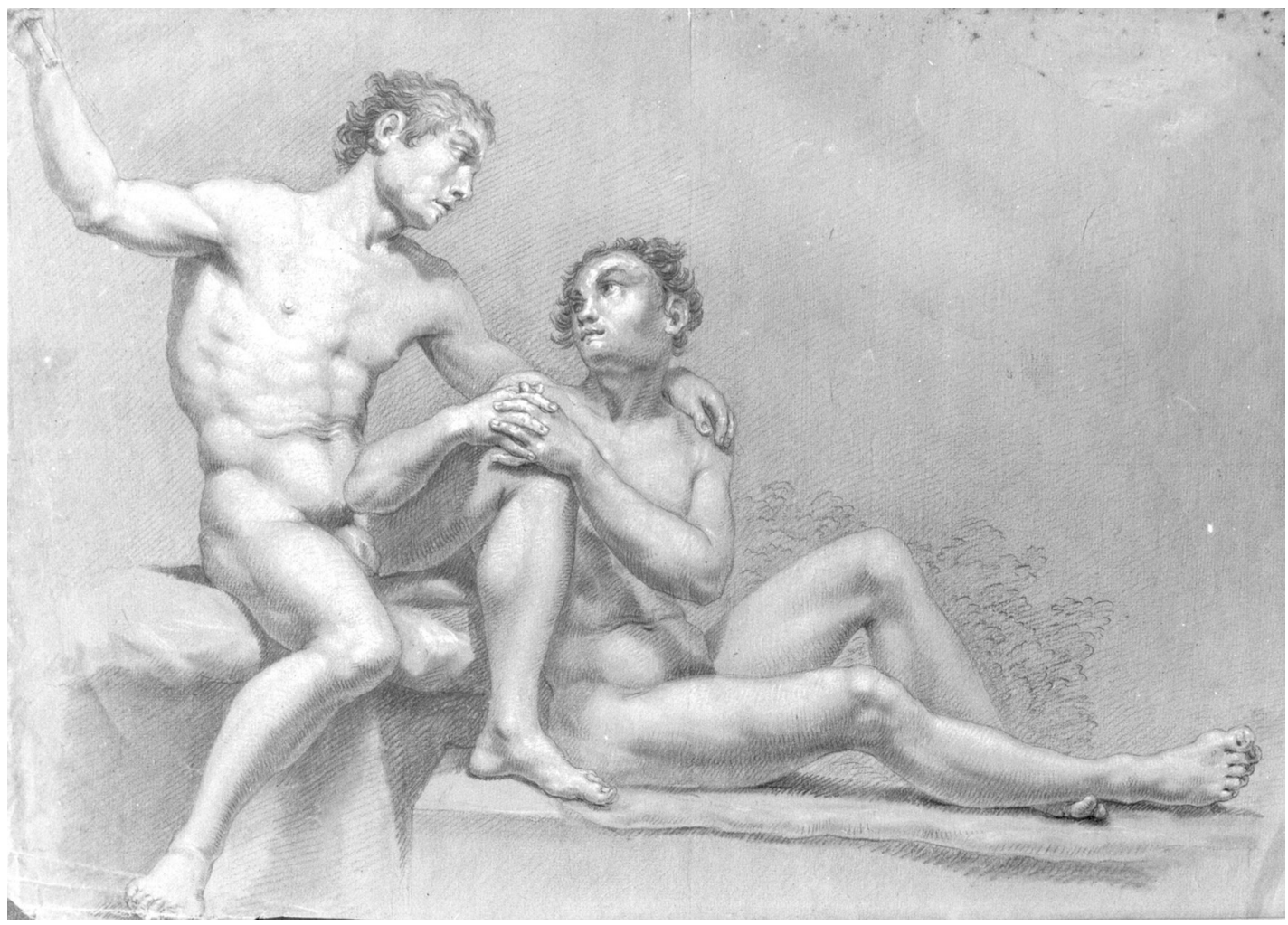

2. José Romá, Academia, 1805. (C) Museo de Bellas Artes de Valencia

descubierto que Romá se presentó al premio de 2. ${ }^{a}$ Clase de Flores y al de 2. ${ }^{a}$ Clase de Pintura, lo que demuestra que no había renunciado a convertirse en "pintor de Historia». Asimismo, esta fuente permite que demos a conocer los temas que debió realizar. El asunto del ejercicio «de pensado» en la 2. ${ }^{\text {a }}$ Clase de Pintura fue: «Abacuc conducido de un Ángel, le lleva el alimento a Daniel al Lago (sic) de los leones» y como «repente»: «La lucha del Ángel con Jacob». El único opositor al que tuvo que enfrentarse fue Vicente Castelló (1787-1860), que ganó y que terminaría convirtiéndose en un serio rival, así como en uno de los mejores pintores activos en Valencia durante la primera mitad del siglo XIX. En cuanto a los temas de la 2. ${ }^{a}$ Clase de Flores, las obras «de pensado» fueron: «Un Dibuxo (sic) para una Cortina de Sagrario en un ala con alguna alegoría del Santísimo Sacramento, y sus adornos y enlaces de Flores para mayor hermosura. Y un Florero [...] pintado al óleo, o al agua copiado del natural». Por lo que respecta a los ejercicios «de repente», el tema fue el mismo para la 1. ${ }^{a}, 2 .^{a}$ y 3. ${ }^{a}$ Clase: «Un Jarrón con diferentes flores naturales a este fin». En este caso, su único contrincante fue Jerónimo Navases (1787-post 1823) que sólo consiguió un voto frente a los quince de Romá ${ }^{\text {. }}$

De las obras realizadas para este Concurso de 1807 , el Museo de Bellas Artes valenciano conserva el ejercicio «de repente», atribuido erróneamente a su hijo José María Romá (doc. 1838-post 1867), que también se dedicó a la pintura de flores ${ }^{6}$. Está realizado con lápiz negro y tiza sobre papel verjurado y mide $471 \times 334 \mathrm{~mm}$. Es un florero compuesto por un jarrón con una guirnalda y un busto, en el que pueden distinguirse una rosa, un clavelón, petunias y otras plantas ornamentales apenas esbozadas que hacen difícil su identificación.

Romá obtuvo el primer premio en Flores en el Concurso General del 13 de diciembre de 1810 (Aldana, 1970: 197). Gracias a la consulta de los documentos manuscritos sabemos que fue el único opositor a esta categoría, debi- 


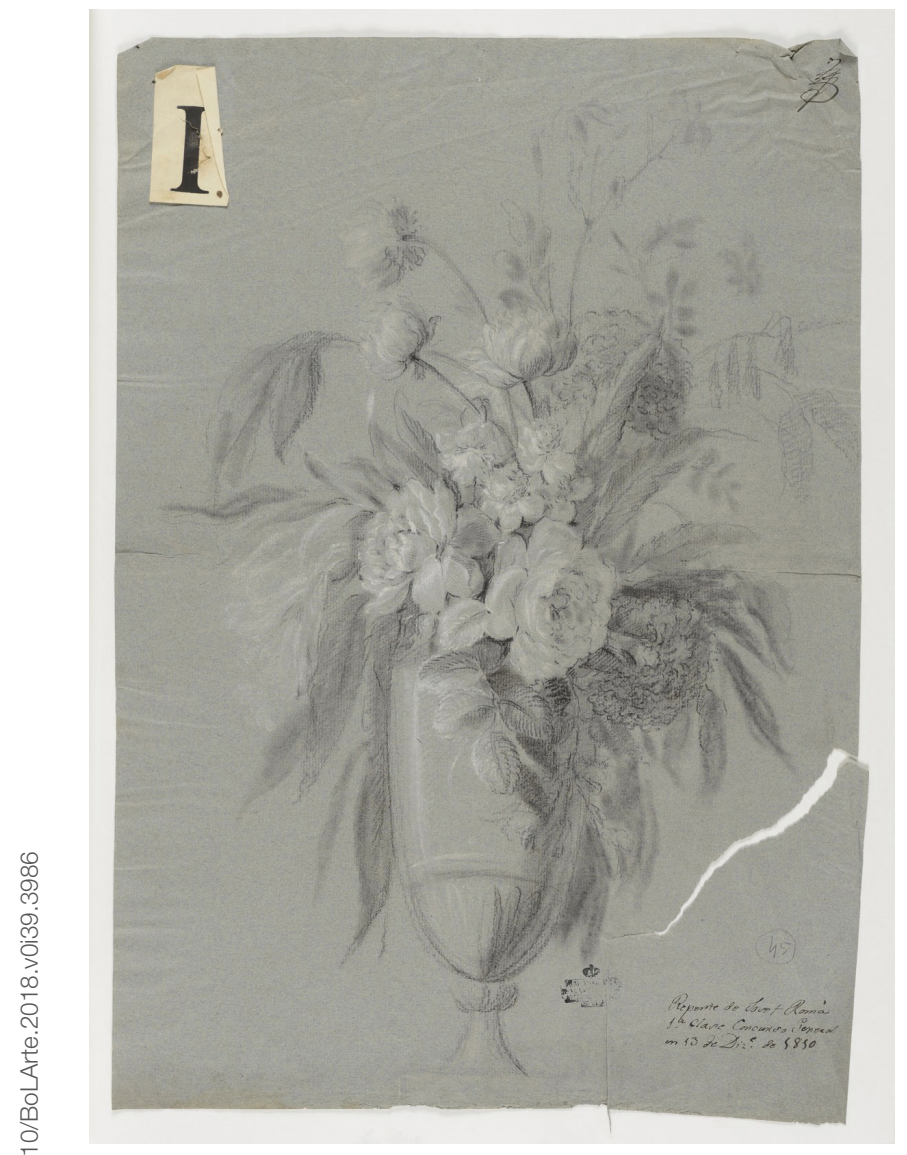

3. José Romá, Jarrón con flores, 1810. @ Museo de Bellas Artes de Valencia

do seguramente al difícil contexto político. Además, aunque no ha sido posible localizar el asunto «de pensado» para el Premio $1 .^{\circ}$ de Flores, sí se ofrece información sobre el tema «de repente». El asunto fue: «Un Jarrón con varias flores naturales, que deberá copiarse exactamente» ${ }^{7}$, expresión significativa que figura por primera vez en el enunciado de estos ejercicios, puesto que desaparece la exigencia de adaptarse a los tejidos.

En el mismo Museo se conservan este «repente» y el lienzo por el que consiguió esta gratificación. El primero [3] también está atribuido erróneamente a su hijo. Es un dibujo realizado con lápiz negro y tiza sobre papel verjurado de 513 x 356 mm, fechado el 13 de diciembre de 1810. Aunque muestra innegables similitudes con el de 1807, el jarrón es más estilizado y se describe con menor detallismo. En cuan- to a las flores, pueden distinguirse una rosa, una peonía, anémonas, tulipanes, viburnos y ranúnculos.

El Jarrón en forma de cornucopia con guirnaldas [4], un óleo sobre lienzo de 83 ×59,5 cm, a pesar de estar firmado, fue atribuido en diferentes ocasiones al afamado pintor Miguel Parra (1780-1846) debido sin duda a su calidad y similitudes estilísticas. A partir de los números que aparecen en el lienzo y cotejándolos con los del Inventario de los bienes de la Academia de 1797-1834, Pérez Sánchez puso fin a las dudas, identificándolo con la obra por la que Romá fue galardonado en 1810. En su opinión, «el perfil complicado del jarrón, con cabeza y busto alado de arpía o sirena, subraya un cierto barroquismo afectado que contrasta con la elegancia neoclásica de otros floreros del momento» (1996: 114-115). No obstante, podemos aportar que tiene evidentes semejanzas con el jarrón diseñado por Ciro Ferri (16341689) que aparece en la publicación Raccolta de vasi diversi [...] (Roma, 1713), de Francesco Aquila, presente desde 1791 entre los fondos bibliográficos de la Academia (Sánchez, 2008: 322-323). Por lo que respecta a las especies botánicas, están representadas con la acostumbrada fidelidad y pertenecen al repertorio habitual de las composiciones de flores académicas valencianas de este período (López Terrada, 2001: 162-183). En la parte superior se disponen dos tulipanes. La primera guirnalda que rodea el jarrón y se extiende hacia el centro comienza por la izquierda con rosas de color rosa, espuelas de caballero dobles, una adormidera, un crisantemo doble, una gran rosa blanca junto a otras amarillas, una anémona coronaria, jazmines amarillos y españoles junto a ranúnculos por la zona inferior y adormideras de un intenso color rojo en el centro. La segunda guirnalda, que se sitúa en sentido inverso, empieza con un tulipán azul, una adormidera vista por detrás, un ejemplar de rosal de cien hojas, dos grandes claveles rojos, narcisos, ranúnculos blancos, otro clavel blanco y rosado, una rama de espuela de caballero doble, una amapola doble, clavellinas e ipomeas.

Avalado por estos premios, en 1815 Romá pidió asunto para optar a Académico de Mérito por la Pintura de Flores, nombramiento que finalmente obtuvo el 3 de agosto de 1817. Aunque el dato ya se conocía, interesa destacar dos aspectos de este reconocimiento. Por una parte, era la oportunidad buscada por muchos artistas para acceder a niveles profesionales y sociales más elevados, ya que el 


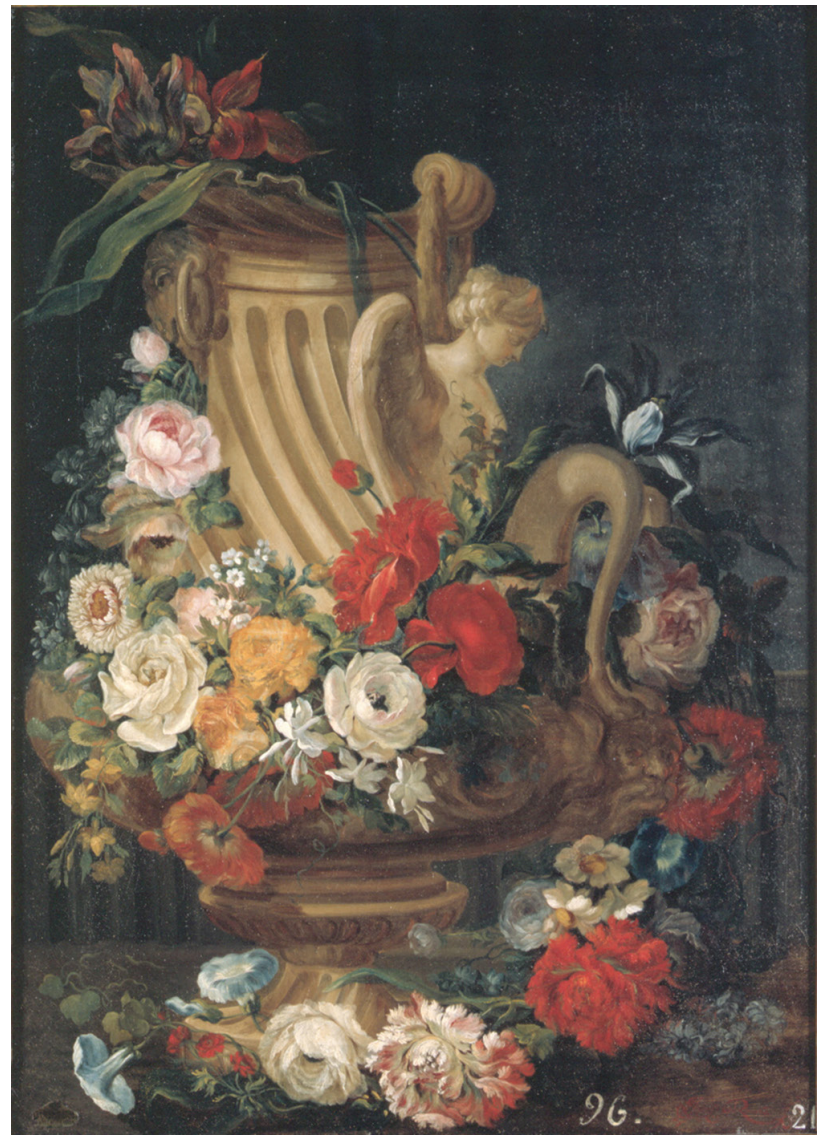

4. José Romá, Jarrón en forma de cornucopia con guirnaldas, 1810. (C) Museo de Bellas Artes de Valencia

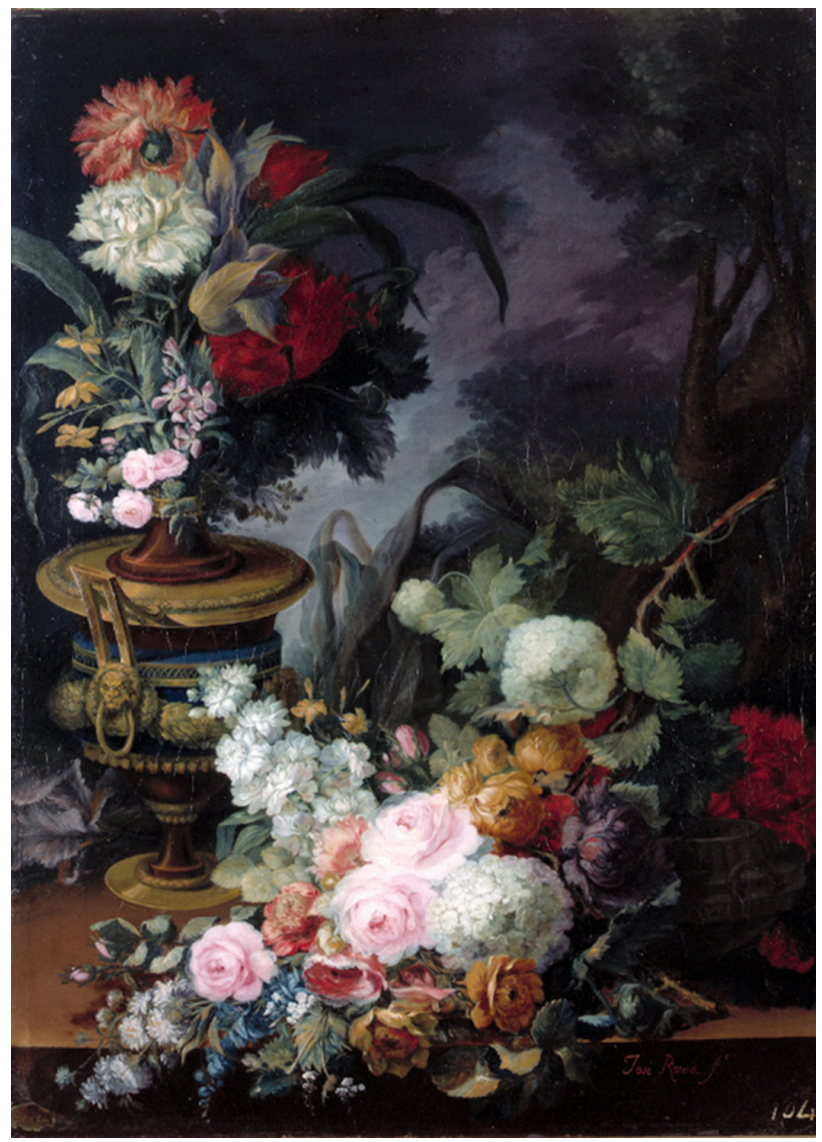

5. José Romá, Florero en un paisaje, 1817. (C) Museo de Bellas Artes de Valencia título además de prestigio, podía garantizar un mejor futuro profesional. En segundo lugar, Romá debió someterse al nuevo reglamento exigido para la creación de Académicos de Mérito en la Sala de Flores redactado por José Antonio Zapata como director del Estudio de Flores y Ornatos, y aprobado el 11 de agosto de 1816 (Aldana, 1970: 286-286, documento n. ${ }^{\circ}$ 18). Con él se pretendía dignificar la distinción de Académico de Flores y tener criterios fijos para juzgar la adecuación al nombramiento, además de centralizar en la Academia los principales ejercicios que garantizasen las aptitudes para la pintura floral.

De las obras exigidas para este reconocimiento, el espléndido Florero [5] que el autor donó a la Academia se encuentra en el Museo de Bellas Artes valenciano. Es un óleo sobre lienzo de 81 × $58 \mathrm{~cm}$, que responde a la tipo- logía de jarrones insertos en un paisaje. Su disposición es sorprendentemente similar al Florero y cesto de flores en un jardín de Miguel Parra, pintor de Cámara desde 1815, que hoy se conserva en La Casita del Príncipe de San Lorenzo de El Escorial ${ }^{8}$. En el lienzo de Romá, sobre un zócalo se levanta un florero neoclásico que contiene un ramo de claveles, tulipanes, jazmines amarillos, alhelíes y rosas. Ocupando todo el ángulo inferior derecho y en sentido oblicuo al jarrón se despliega un ramo que mezcla luminosas y contrastadas especies botánicas. Entre ellas pueden distinguirse una rama de viburno, rosas amarillas y rosas, jazmines amarillos, anémonas, amapolas, claveles, espuelas de caballero y una rama de alhelíes dobles blancos.

La calidad de esta y otras obras de los artistas formados en la Escuela de Flores valenciana explican el prestigio 


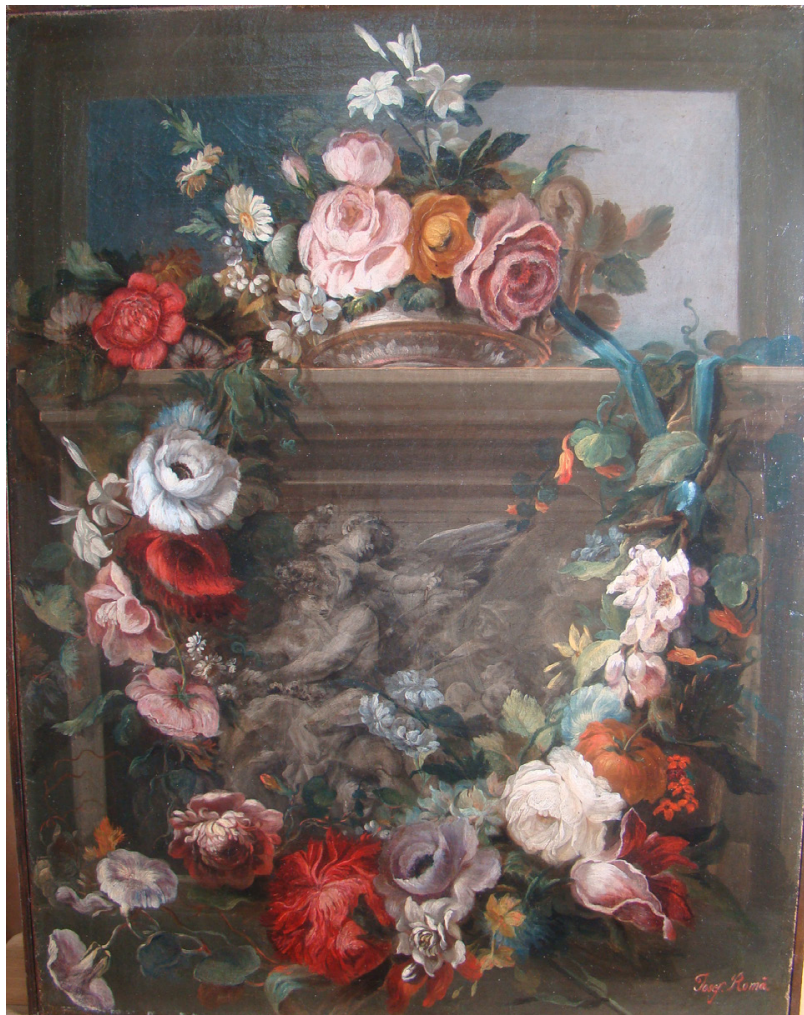

6. José Romá, Florero con relieve escultórico. Madrid, colección particular

alcanzado en la época por sus composiciones. Este hecho, junto al deseo de control de la institución a la que pertenecían, llevó a los pintores José Antonio Zapata, Miguel Parra, Antonio Colechá y al propio José Romá a solicitar una petición, fechada el 6 de marzo de 1819, «para que no puedan ejercer de pintores de flores quienes no hayan cursado los estudios en la Academia de San Carlos» (Aldana, 1970: 288-289).

Como pintor de flores, género en el que sin duda destacó y por el que se le recordaría, Romá debió realizar un buen número de obras destinadas a particulares. Este parece ser el destino de la Pareja de jarrones neoclásicos y cestillos de flores, dos óleos sobre lienzo firmados de $64 \mathrm{x}$ $82 \mathrm{~cm}$ cada uno $^{9}$. El mismo destino parece tener el cuadro que ahora se da a conocer [6]. También es un óleo sobre lienzo de $63 \times 48 \mathrm{~cm}$, perteneciente a una colección particular madrileña. Para el análisis técnico se emplearon principalmente lentes de aumento (optivisores de 4x y lupas de 10x) y luz ultravioleta ${ }^{10}$. El cuadro fue pintado en lienzo de apariencia de lino realizado en telar manual por la irregularidad de los hilos, de trama y urdimbre de 15-16 hilos por $\mathrm{cm}^{2}$, muy utilizada entre finales del siglo XVIII y principios del XIX. También el tono de la coloración de las fibras responde a esta época por la foto-oxidación de las mismas a los factores degradantes ambientales. Montado sobre un bastidor moderno, está reentelado con tela industrial de trama más fina y regular y aparentemente es de algodón. La radiación no visible ultravioleta permitió distinguir la autenticidad de la firma y los repintes en tonos de fluorescencia más oscuros. En este examen se pudieron apreciar también los barnices, muy excesivos en general, de forma irregular en cuanto al reparto en la superficie. También se evidenciaron claramente los «barridos» de las veladuras y la eliminación de elementos pintados. Como es sabido, las veladuras, al llevar mucho barniz y poco pigmento son muy delicadas y se remueven con facilidad en las limpiezas, reaccionando como los barnices. En este caso, los barridos, al parecer de una limpieza antigua, han afectado principalmente a la escena central en grisalla y a la aplicación de las capas de pintura muy diluidas que conferían luminosidad y transparencia a las flores, provocando evidentes diferencias en su aspecto actual. Mientras en algunas aún se aprecia un tratamiento detallista y una representación realista, otras aparecen resueltas de forma más tosca, sin apenas matices ni volumen.

En cuanto a la composición del cuadro, el elemento central lo ocupa un plinto con un relieve escultórico frontal sobre el que se dispone un jarrón del que prácticamente solo se aprecia su parte inferior. Este recipiente se sitúa ante un espacio enmarcado de difícil definición, que presenta un fuerte contraste de iluminación. De ambos lados de este jarrón cuelga una rica guirnalda de flores, iniciada a la derecha por una cinta azul, que enmarca la escena central del plinto realizada en grisalla. Como es habitual en los cuadros de flores del artista, los arreglos florales son el resultado de una cuidadosa disposición de diferentes variedades. Los colores de las flores y la intensidad de los tonos son similares a las composiciones de Romá que se conservan en el Museo valenciano. También es parecido el repertorio botánico utilizado. En el jarrón pueden reconocerse ejemplares de rosas de color rosa, una amarilla y una adormidera doble, jazmines españoles en la parte superior, celindas y margaritas. En el extremo izquierdo aparecen en penumbra flores y hojas de muy difícil identificación debido básicamente a los 


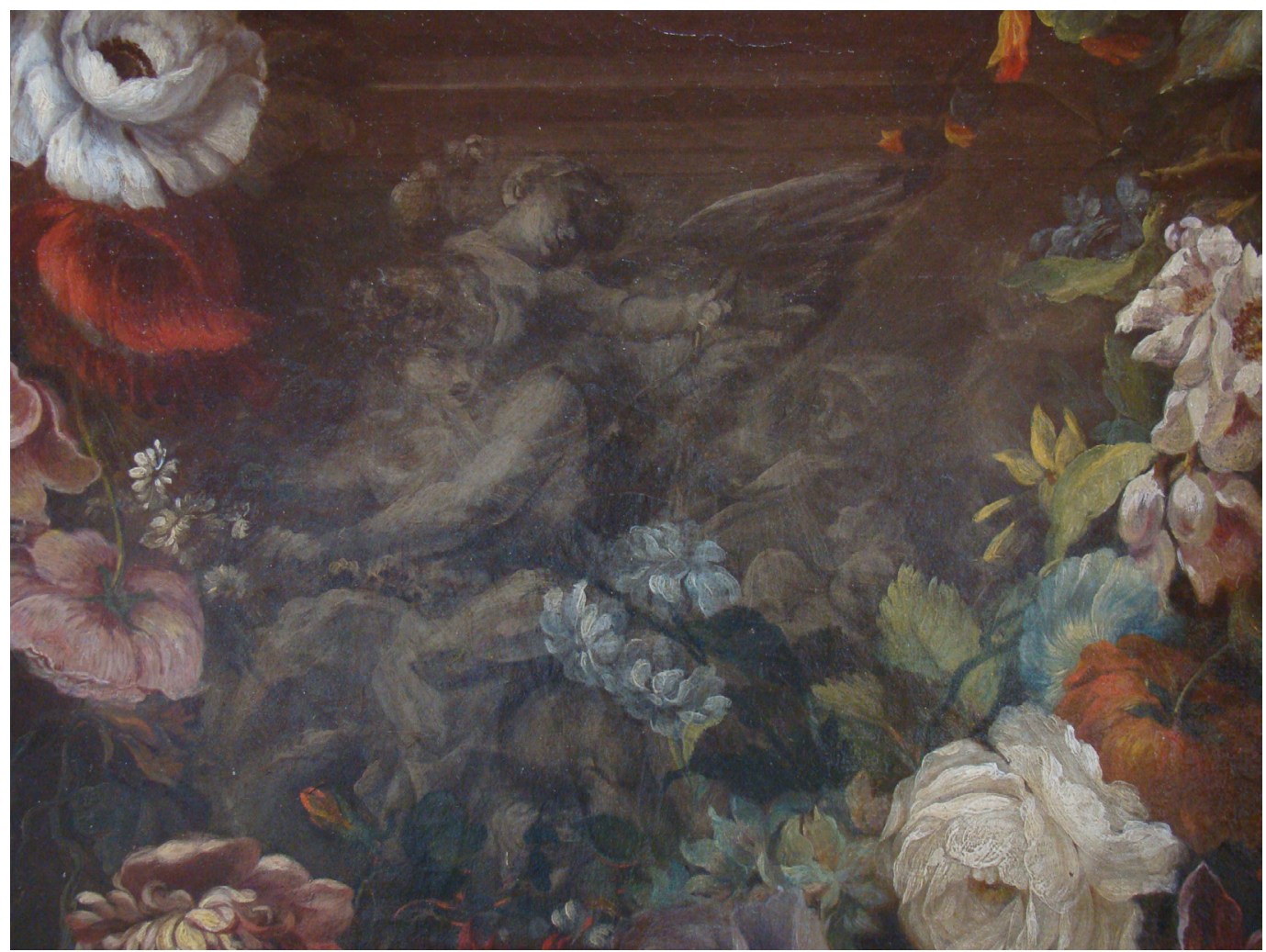

7. José Romá, detalle de la grisalla del Florero con relieve escultórico. Madrid, colección particular

repintes, salvo la flor rojiza que es una anémona. La guirnalda comienza por la parte derecha por una rama de la capuchina y otra de almendro con sus características flores; ejemplares de jazmín y lo que ahora ha quedado reducido a una silueta azulada. En origen, podría tratarse de una arañuela, pues estos mismos colores vuelven a aparecer en la última flor de esta colgadura, mostrando un perfil más definido. La guirnalda continúa con un ranúnculo asiático y un grupo de florecillas rojas pintadas con ciertas licencias, que podrían ser alhelíes. El ángulo inferior se reserva para una llamativa rosa blanca, muy retocada, y un tulipán. En la parte central se sitúan una amapola doble y una gran peonía roja; entre ellas, un narciso doble y jazmines amarillos. En el ángulo inferior derecho hay una rama de ipomeas. Sobre ella, extendiéndose por el extremo izquierdo se despliegan las ramas y las pequeñas flores amarillas de la flor de canario. El entrelazado floral se completa con un ejemplar rosado de anémona doble, la flor mejor representada desde el punto de vista botánico y una de la más preservadas de los «barridos» de toda la composición; rosas de apariencia un tanto marchita, una adormidera roja, una amapola doble blanca y jazmines españoles. De todas estas plantas, las que se encuentran sin duda más desdibujadas por el efecto de la restauración son las que ocupan la escena en grisalla y que quizá podrían darnos la clave de la misma. Todo parece indicar que son narcisos.

Como en otros cuadros de la Escuela valenciana de Flores, el espacio central del cuadro lo ocupa una representación en grisalla. Ya se ha señalado que Romá incluyó motivos similares en otras composiciones, como la figura de Hebe -la diosa de la juventud y escanciadora del Olimpo- de su Guirnalda de flores con motivo escultórico del Museo del Prado [1]. En este sentido parece interesante señalar que la mitología no fue un tema ajeno a su producción, como veremos más adelante. En este cuadro [7], la escena podría representar el mito de Narciso y Eco, tal 
como indican las flores que se sitúan ante ella. Narciso sería el hermoso joven que se desplaza hacia la izquierda, como alejándose de la figura casi imperceptible de Eco, mientras que a su espalda se encontraría Cupido, disparando su flecha de amor hacia la ninfa. La versión más conocida es la que proporciona las Metamorfosis de Ovidio (III, 339-510), relato que ilustraron multitud de artistas. En él, Narciso se presenta como un joven de extraordinaria belleza, pero que despreciaba el amor. Su enamorada más desgraciada fue la ninfa Eco, que se dejó consumir de manera que sólo quedó de ella su voz afligida. En concreto, las fuentes literarias, como la Segunda parte del Teatro de los dioses de la Gentilidad de Baltasar de Vitoria (1737-1738) presente en la biblioteca de la Academia, apuntan que, consumida de amor por el hermoso Narciso, enflaqueció tanto que solo quedó de ella la voz, convirtiéndose sus huesos en piedras, tal como parece representar Romá. El desenlace de la historia es bien conocido. Los numerosos enamorados rechazados por Narciso pidieron venganza a los dioses. Como castigo, el joven se enamoró tan perdidamente de su propia imagen reflejada en el agua que, olvidándose del resto del mundo, murió, siendo su cuerpo transformado en la flor que lleva su nombre.

Sin abandonar esta especialidad, José Romá continuó su trayectoria y alcanzó el ansiado grado de Académico de Mérito por la Pintura el 30 de noviembre de 1826. Para ello, se valoró su trayectoria como dibujante y presentó un cuadro cuyo asunto era «Sorpresa Lucrecia por Sexto Tarquino en su propia cama resiste con su virtud sus depravados intentos", votando todos los miembros de la Junta a su favor $^{11}$. Es un óleo sobre lienzo de 135,8 x $91 \mathrm{~cm}$, conservado en mal estado en el Museo de Bellas Artes de Valencia ${ }^{12}$. El tema ilustra el momento más dramático de la historia de Lucrecia contada, entre otros, por Tito Livio y Ovidio en sus Fastos y representada por muchos pintores. La honorable y bella dama romana era deseada por Sexto, el hijo del monarca Tarquino el Soberbio (534-510 a.C.). Los rechazos continuos de la fiel esposa, que estaba casada con Colatino, provocaron la cólera del joven que, una noche, aprovechando la ausencia del marido, la violó, amenazándola de muerte. Lucrecia contó lo sucedido a su familia y se suicidó, siendo vengada por los Lucrecios. Este hecho sería el motivo que pondría fin a la monarquía en Roma y permitiría la instauración de la República. Desde el punto de vista compositivo y lumínico, el cuadro es muy similar a la versión realizada por Tiziano en 1570 del Museo de Bellas Artes de Burdeos. Es posible que el pintor valenciano lo conociera a través de la estampa grabada por Cornelis Cort en 1571.

Por entonces, Romá ya había iniciado su carrera docente pues, debido al delicado estado de salud de José Antonio Zapata, actuó frecuentemente como su sustituto no sólo en la Sala de Flores, sino también en la de Principios, Yeso y Natural. También se dedicó a la enseñanza fuera de la Academia, encargándose de dirigir la Sala de Dibujo del Real Seminario de Nobles de San Pablo y con una escuela particular de dibujo y pintura en su propio domicilio ${ }^{13}$.

La calidad de su producción y su labor docente explican que fuese uno de los artistas propuestos para ocupar la dirección de la Sala de Pintura en 1835, cargo que finalmente consiguió Vicente Castelló tras una reñida competición. No obstante, su prestigio le valió el nombramiento de director de la Sala de Flores en 1837, al jubilarse Zapata, puesto que ocupó hasta su muerte en 1852. Durante esta etapa se hizo evidente la escasa utilidad que los Estudios de Flores y Ornatos tenían para la industria sedera, acentuándose la inclinación hacia la pintura de flores. Se impuso así una nueva tendencia decorativa floral totalmente desligada del concepto aplicado que había regido durante el siglo XVIII, al menos en su enseñanza teórica. Unos años más tarde se produjo la reforma de los planes de estudio de la Academia valenciana, siguiendo la realizada en la de San Fernando. Se buscaba con ella una nueva estructuración de las materias impartidas, añadiendo a las ya tradicionales aquellas especialidades que exigían los nuevos tiempos. Casado ofrece la plantilla del profesorado de la Academia valenciana en agosto de 1850, tras el nuevo plan de estudios. En ella, Romá figura como profesor de «dibujo lineal y adorno», materia que se encontraba entre los «Estudios elementales», junto al "dibujo aplicado a artes y fábricas», "aritmética y geometría propias para el dibujo», "dibujo de la figura» y «perspectiva y paisaje» (1997: 42-43).

Existen dos noticias destacables sobre los últimos años de actividad de José Romá. La primera hace referencia a su participación, junto a otros reconocidos artistas de la época, en las exposiciones de pintura organizadas por la Real Sociedad Económica de Amigos del País de Valencia de 1848 y 1851 (Roig Condomina, 2001: vol. II, 923-933). En la primera de ellas, intervino junto a su hijo José María 
Romá, introduciéndolo de esta forma -como otros artistas de la época- en los círculos culturales valencianos. En la celebrada en 1851, fue uno de los pocos artistas valencianos de mayor popularidad que se presentaron.

La última actuación de la que tenemos noticia sobre José Romá se llevó a cabo durante la visita de la Infanta María Luisa Fernanda y el Duque de Montpensier a la Academia de Bellas Artes de Valencia en 1852. En esta ocasión, el pintor les entregó dos cuadros de flores de su mano que se encontraban en las galerías del Museo. Lamentablemente se desconoce su paradero actual. El dato que sí sabemos con seguridad es que falleció unos meses después, pues su necrológica apareció publicada en el Diario Mercantil de Valencia el 26 de agosto de 1852 (Alba, 1999: 901).

Además de cultivar la pintura de flores y de Historia, Romá también fue un gran retratista. Uno de sus mejores exponentes es el Retrato de Benito Espinós [8]. Este óleo sobre lienzo de $80 \times 61 \mathrm{~cm}$ se encuentra en el Museo de Bellas Artes de Valencia. En él se representa al primer director de la prestigiosa Escuela de Flores y Ornatos, optando más por una descripción minuciosa que por la idealización. Como otros muchos retratos académicos, la recia figura del maestro se muestra de medio cuerpo, con las herramientas de su trabajo: la paleta, el tiento y un pincel en su mano derecha. Tras él, a la izquierda, se distingue en lienzo de flores. Esta manera de representarse "con los instrumentos de su arte en mano, tal como Carducho había advertido, lo encontramos a lo largo del siglo XVII», y subraya «el deseo del artista»-o de su retratista- de inscribirlo «en las filas de hombres memorables que deben ser recordados por su condición», sin «reparo en mostrar su profesión» (Gacto, 2009). Por otra parte, esta obra también podría inscribirse dentro del llamado «retrato de artista» que cobró una especial importancia a partir del siglo XIX. Se trata de efigies ejecutadas por los pintores a otros compañeros de profesión de su círculo afectivo o social más próximo (Díez, 1997: 39-40). El aspecto donde se pone más claramente de manifiesto la falta de idealización del retrato es en la representación de su rostro. En él se hace evidente la pérdida de visión de un ojo que, sin embargo, no restó destreza a su oficio. A juzgar por la edad que representa, unos sesenta años, algunos autores opinan que debió realizarlo entre 1810 y 1814, «fecha en la que un ataque de apoplejía a la que se añadió después una ceguera total, le impidió seguir con sus enseñanzas y finalmente

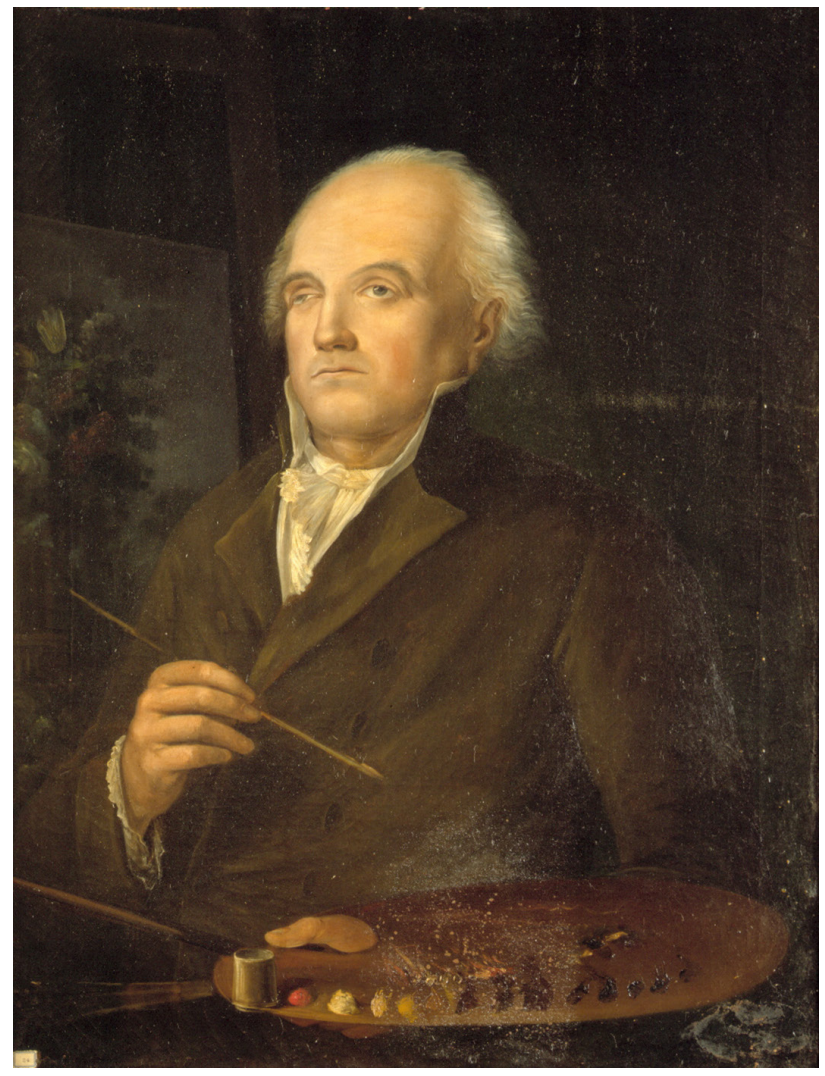

8. José Romá, Retrato de Benito Espinós, ca. 1828. (C) Museo de Bellas Artes de Valencia

le impidió pintar» (Aliaga, 2004: 222). No obstante, dada la inexperiencia que por estos años poseía Romá y la indudable calidad de la obra, parece más probable que el cuadro se realizara tras la muerte de Espinós a finales de la década de 1820 (Alba, 2004: 2044).

Se conocen además cuatro retratos de Isabel II de Romá. Cronológicamente, el primero de ellos y el de peor factura es el de /sabel II niña, que se encuentra en la Universitat de València y está fechado hacia 1841 (Benito, 2008: vol. II, 128-129). El segundo Retrato de Isabel /I niña, de técnica excelente, es propiedad de la Diputación Provincial de Valencia [9]. En este caso, vuelve a estar representada de cuerpo entero con traje de corte y adornada con exquisitas joyas. Apoya su brazo derecho sobre una mesa vestida que contiene los símbolos de la monarquía: la corona y el cetro, que descansan sobre un cojín. Al fondo se distingue el trono con esfinges en sus brazos y cabezas de león 


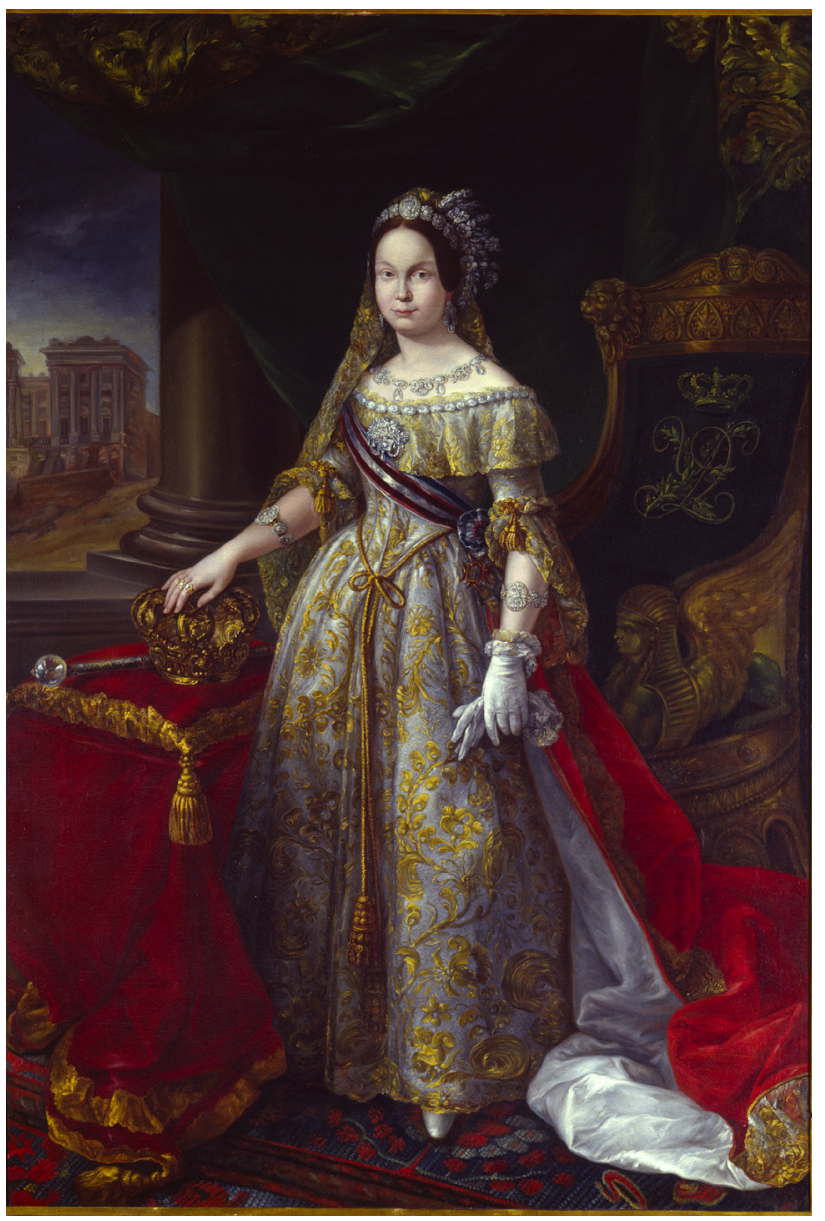

9. José Romá, Retrato de Isabel II, niña, ca. 1843. @ Diputación de Valencia

a ambos lados, más amplias cortinas. En la parte izquierda hay una ancha columna junto a un ventanal que permite ver un gran edificio en perspectiva que parece el propio Palacio Real. Como efigie oficial se sitúa en la tradición del retrato de corte borbónico (Jerez, 2007: 68-70). Este óleo sobre lienzo de 183,5 x 123,5 cm, debió ejecutarse hacia 1843, año en que Isabel II se convirtió en reina de España. Se trata de una copia del realizado por Bernardo López Piquer, actualmente expuesto en el Palacio de Cervelló, que fue recibido con gran entusiasmo por la crítica y el público (Gil, 1992: 132). El tercer Retrato de Isabel II joven figura entre los fondos del Museo de Bellas Artes de Valencia. Es un óleo sobre lienzo de 185 x 122,5 cm, fechado hacia 1844 (Alba, 220: 2034). En este caso, aparece retratada algo mayor, posiblemente cuando la reina proclamó su mayoría de edad. Desde el punto de vista compositivo, presenta indudables semejanzas con el prototipo de retrato oficial de la reina creado por Federico de Madrazo en 1846. El último Retrato de Isabel II, un óleo sobre lienzo de 184 × 120 cm, atribuido por Catalá a José Romá por su similitud con el cuadro anterior, se encuentra en el Museo de la Ciudad de Valencia (1997: 91-92) ${ }^{14}$.

Gracias a la información procedente del Catálogo de objetos que contiene el Real Museo Militar a cargo del cuerpo de artillería (1856: 10, n. 13 y 14), podemos dar a conocer que también realizó dos copias del «retrato del Emperador Carlos V, que, hecho por Ticiano, se encuentra con el número 765 en el Real Museo de Pinturas del Prado» y del «retrato de Doña Isabel de Portugal, esposa del Emperador Carlos V», que "se halla en el Real Museo de pinturas del Prado, con el n. ${ }^{\circ} 878$, hecho por Ticiano». La referencia de estos números se encuentra en el Catálogo de los Cuadros del Real Museo de pintura y escultura de S. M. [...] de Madrazo (1850: p. 179, n. ${ }^{\circ} 765 ;$ 205, n. $\left.{ }^{\circ} 878\right)$, donde están brevemente descritos. A partir de estas indicaciones, puede concluirse que los cuadros de Tiziano copiados fueron el Retrato de Carlos V con perro, de 1533, y el de La Emperatriz Isabel de Portugal, de 1548, ambos en el Museo del Prado.

Además de estos retratos, el artista valenciano realizó otros destinados a particulares. El primero, un óleo sobre lienzo de 62 × 49,5 cm firmado en 1824, es un Retrato de una niña que apareció en el mercado artístico en septiembre de 2000. Ocho años después, salió a subasta otro óleo sobre lienzo firmado, de $90 \times 75 \mathrm{~cm}$, que representa a una Joven con una cesta de uvas $^{15}$.

Para concluir este recorrido por la producción de Romá quisiera detenerme brevemente en su labor como dibujante. En el Museo de Bellas Artes de Valencia se conservan seis magníficos dibujos firmados por el autor, que debió realizar cuando ocupaba el cargo de director de la Sala de Flores. Representan complejas alegorías de los primeros seis meses del año protagonizados, respectivamente, por Juno (enero); Neptuno (febrero); Marte (marzo); Venus (abril); Apolo (mayo) y Mercurio (junio) ${ }^{16}$. Una buena muestra es la Alegoría del mes de febrero [10] en la que Neptuno, coronado y con un tridente, acompañado por una ballena y apoyado sobre una gran concha, se alza sobre un alto pedestal decorado con animales marinos. La parte inferior 
se reserva para la representación de signo de piscis, con tritones e hipocampos a los lados. El fondo lo ocupa una vista parcial de un gigantesco barco, que alude a la protección del dios del mar sobre los navegantes. Esta destreza no es tan apreciable en los que ideó y proporcionó para que fueran grabados e ilustraran la nueva edición de la Historia General de España de Juan de Mariana (Valencia: Imprenta de Manuel López, 18 vols. 1830-1841). Comparando estas obras con las veinticuatro estampas del Museo Nacional de Cerámica y Artes Suntuarias «González Martí» de Valencia se puede afirmar que pertenecen a la misma publicación ${ }^{17}$. Se ha localizado además otra estampa suelta que lleva impresa la leyenda: Imagen de la Virgen del Carmen venerada por su Cofradía en su $R^{\prime}$ Convento de Vala, entre el escudo carmelitano. En ella se indica que fue dibujada por José Romá y grabada por Julián Más (1770-1837) en Valencia en $1833^{18}$.

Toda la información expuesta ha pretendido profundizar en la brillante trayectoria profesional de este artista, cuya memoria ha quedado ensombrecida por otros grandes pintores del momento como Benito Espinós o Miguel Parra. El conocimiento de la figura de José Romá puede contribuir a ampliar la visión, no sólo de la producción de la Escuela valenciana de Flores, sino también del arte académico valenciano y español de la primera mitad del siglo XIX.

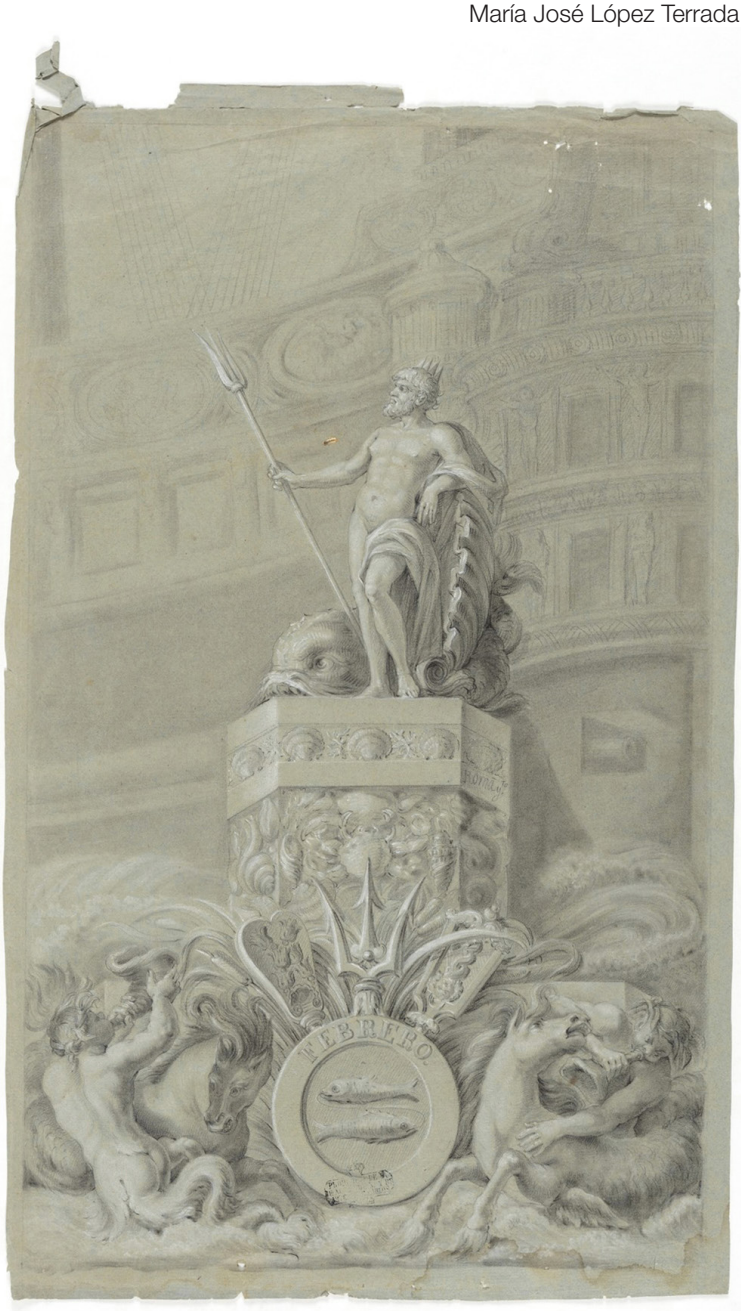

10. José Romá, Alegoría del mes de febrero. (C) Museo de Bellas Artes de Valencia

\section{Notas}

1 Véase, entre otros, Aldana, 1971: 197-198; López Terrada, 2001: 248-249 y Alba, 2003: 2031-2058.

2 Libro de actas de la Real Academia de San Carlos años 1801-1812. Junta Ordinaria en 27 de abril de 1805. Archivo de la Real Academia de Bellas Artes de San Carlos (ARABASC, Valencia).

3 Alba, 2004: p. 2035. Espinós, 1984: vol. II, 160, n. ${ }^{\circ}$ 472. Las restantes Academias también se reproducen en ambos estudios.

4 Entre los trabajos dedicados a esta escuela se encuentran el de Aldana, 1970 y López Terrada, 2001, donde se recoge la bibliografía anterior. Para las últimas aportaciones, ver Sánchez, 2008, aunque se detiene en 1818.

5 Junta pública de 1807. Continuación de las Actas de la Academia de las nobles Artes Establecida en Valencia con el título de San Carlos y relación de los Premios que se distribuyó en su Junta Pública de 4 de noviembre de 1807 (ARABASC, Valencia), legajo 126/4/7.

6 López Terrada, 2001: 250. En varias ocasiones, como en la obra de Boix, 1877: 57 y en la de Ossorio, ed. 1883: 594-595, se han atribuido las obras de José Romá del Museo de Bellas Artes de Valencia a su hijo.

7 Libro de actas de la Real Academia de San Carlos años 1801-1812. Junta general en 5 y 6 de diciembre de 1810 y Junta Pública en 13 de diciembre de 1811, (ARABASC, Valencia). Según Garín, 1945: p. 180, la fecha de este último documento corresponde en realidad al año 1810.

8 López Terrada, 2001: 347, fig. 51. Sobre esta composición, también puede verse el artículo de 2013 de la misma autora.

9 Requena, 2003-2004, n. 29. En el mercado artístico han ido apareciendo otras composiciones de flores y bodegones atribuidas a Romá cuyo estudio contribuirá, sin duda, a conocer mejor esta faceta pictórica.

10 Quisiera expresar mi agradecimiento a la artista, profesora y restauradora María Gómez Rodrigo por la inestimable ayuda que me brindó para realizar este análisis.

11 Junta Ordinaria de 30 de noviembre de 1826. La noticia también se recoge en el Libro de individuos desde su creación (1768-1847), p. 143 (ARABASC, Valencia). 
12 Fue donado por el autor a la Academia al recibir este nombramiento. Se reproduce en Alba, 2004: 2058.

13 Según Aldana, 1970: 198 tuvo un estudio en su domicilio particular «en el número 66 de la calle de las Calabazas, cerca del edificio de la Lonja; y en 1847 [...] en el mismo lugar». Poco tiempo después debió cambiar de residencia, pues Boix, 1849: 334, indica que vivía en la calle de San Pablo n. 2.

14 El Retrato de Isabel II joven, que actualmente se encuentra en el Palacio de Cervelló no es obra de Romá sino una copia de su original que figuraba en el Museo de Bellas Artes de Valencia. Recientemente se ha descubierto que fue realizada por Antonio Cortina (1841-1890) en 1859. En: http://antoniocortina. blogspot.com.es/2015/01/el-retrato-de-isabel-ii-joven-propiedad.html (3-12-2015).

15 La primera obra fue subastada por Badum Kunsthandel Bamberg, Alemania, el 2 de septiembre de 2009, lote n. ${ }^{\circ}$. La segunda, lo hizo en Subastas Bilbao $X X I$, el 4 de marzo de 2008, lote 236.

16 Hay otro dibujo de la Alegoría del mes de enero, n. inv. 9700 que aparece como obra de Romá, pero que no está firmado y no parece ser suyo.

17 Perales del Río, 2004, n. ${ }^{\circ}$ 28, pp. 39, 281-288, 309-312.

18 Seis ejemplares de esta estampa se encuentran en el depósito académico digital de la Universidad de Navarra.

\section{Bibliografía}

ALBA, Ester (1999), La pintura y los pintores en la prensa valencia de los reinados de Fernando VII e Isabel II, Tesis de Licenciatura de la Universitat de València, Valencia.

- (2004), La pintura y los pintores valencianos durante la Guerra de la Independencia y el reinado de Fernando VII (1808-1833), Tesis doctoral de la Universitat de València, Valencia.

ALDANA, Salvador (1970), Pintores valencianos de flores (1766- 1866), Instituto Alfonso el Magnánimo, Valencia.

- (1998), La Real Academia de Bellas Artes de San Carlos de Valencia. Historia de una institución, Real Academia de Bellas Artes de San Carlos, Valencia.

ALIAGA, Joan (2004) (com.), L'Acadèmia de Santa Bàrbara i la Reial de les Tres Nobles Arts de San Carles. Cent Anys de Ensenyament, Universitat Politècnica de València, Valencia.

BENITO, Daniel (2008) (ed.), La Universitat de València y su patrimonio cultural. Materia Preciosa, 2 vols., Universitat de València, Valencia.

BOIX, Vicente (1849), Manual del viagero (sic) y guía de los forasteros en Valencia: por Don Vicente Boix, cronista de la ciudad, Imprenta de José Rius, Valencia.

- (1877), Noticia de artistas valencianos del siglo XIX, Imprenta Alufre, Valencia.

CASADO, Esteban (1997), «La huella de la Academia en la pintura valenciana del siglo XX», en DíEZ, José Luis (com.), Maestros de la pintura valenciana del siglo XIX en el Museo del Prado, Madrid, Museo del Prado, pp. 37-49.

CATALÁ, Miguel Ángel (1997), El Museo de la Ciudad su historia y colecciones, Ajuntament de València, Valencia.

CATÁlOGO (1850), Catálogo de los Cuadros del Real Museo de pintura y escultura de S. M. redactado con arreglo a las indicaciones del Director Actual de este Real Establecimiento D. Pedro de Madrazo, 3. ${ }^{a}$ ed., Imprenta de Don José María Alonso, Madrid.

CATÁLOGO (1856), Catálogo de objetos que contiene el Real Museo Militar a cargo del cuerpo de artillería, Imprenta Tejado, Madrid.

CONTINUACIÓN (1802), Continuación de las Actas de la Real Academia [...] de San Carlos, y relación de los premios que distribuyó en su junta pública de 12 de noviembre de 1801, Oficina de D. Benito Monfort impresor de la Academia, Valencia.

CONTINUACIÓN (1805), Continuación de las Actas de la Real Academia [...] de San Carlos, y relación de los premios de 4 de noviembre de 1804, Benito Monfort, Valencia.

DíEZ, José Luis (1997), «La imagen del artista en la pintura española del siglo XIX», en Artistas pintados. Retratos de pintores y escultores del siglo XIX en el Museo del Prado, Museo Nacional del Prado, Madrid, pp. 39-61.

ESPINÓS, Adela (1984), Museo de Bellas Artes de Valencia. Catálogo de dibujos. 2 vols, Ministerio de Cultura, Madrid.

GACTO, Marina (2009), «El retrato del artista creador en la segunda mitad del siglo XVIII», en Congreso Internacional Imagen Apariencia, Universidad de Murcia, Murcia.

GARÍN, Felipe María (1945), La Real Academia valenciana de Bellas Artes. El movimiento academicista europeo y su proyección en Valencia, Real Academia de San Carlos, Valencia.

GIL, Rafael (1992), El món de Goya y López en el Museu Sant Pius V, Generalitat Valenciana, Valencia. 
JEREZ MOLINER, Felipe (2017), «La imagen representada: retratos y autorretratos en los fondos de la Diputación de Valencia», en GIL, Rafael (com.), Memoria de la Modernidad. La colección patrimonial de la Diputación de Valencia, Diputación de Valencia, Valencia, pp. 54-121.

LÓPEZ TERRADA, María José (2001), Tradición y cambio en la pintura valenciana de flores 1600-1850, Ayuntamiento de Valencia, Valencia. - (2013), «La pintura de flores de Miguel Parra (1780-1846)», Archivo Español de Arte, tomo LXXXVI, n. ${ }^{\circ}$ 342, pp. $123-142$.

LUNA, Juan J. (2008), El bodegón español en el Prado. De Van der Hamen a Goya, Museo Nacional del Prado, Madrid.

OSSORIO, Manuel (ed. 1883), Galería biográfica de artistas españoles del siglo XIX, Madrid.

OVIDIO, Metamorfosis. Ed. bilingüe con texto revisado y traducido por Antonio Ruiz de Elvira. 3 vols., Alma Mater, Barcelona, 1964.

PERALES DEL RíO, Isabel (2004), “Catálogo y apéndices», en ALEJOS, Asunción, et al., Catálogo de estampas valencianas del Museo Nacional de Cerámica y Artes suntuarias «González Martí», Ministerio de Cultura, Madrid, pp. 55-308.

PÉREZ SÁNCHEZ, Alfonso E. (1996) (com.), Naturalezas muertas y flores en el Museo de Bellas Artes de Valencia, Generalitat Valenciana, Valencia.

PÉREZ SÁNCHEZ, Alfonso Emilio (1997), «La pintura valenciana de flores», en FRANCH, Ricardo et al., El arte de la seda en la Valencia del siglo XVIII, Fundación Bancaja, Valencia, pp. 31-47.

PORTÚS, Javier (2007) (ed.), Lo fingido verdadero. Bodegones españoles de la colección Naseiro adquiridos para el Prado, Museo Nacional del Prado, Madrid.

REQUENA, José Luis (2003-2004), «José Romá (1784-1847), Pareja de jarrones neoclásicos de flores y cestillos con flores» en CHERRY, Peter et al., Naturalezas muestras españolas de los siglos XVII al XX, Caylus, Madrid, n. ${ }^{\circ}$ 29, s. p.

ROIG, Vicente (2001), «La Real Sociedad Económica del País de Valencia como promotora de las Bellas Artes: el ejemplo de las exposiciones del siglo XIX», en Real Sociedad Económica de Amigos del País. Anales 1999-2000, vol. II, Real Sociedad Económica de Amigos del País, Valencia, pp. 925-933.

SÁNCHEZ, Andrés (2008), La pintura de bodegones y floreros en España en el siglo XVIII, Fundación Arte Hispánico, Madrid. 
